https://helda.helsinki.fi

\title{
Sharing risk experiences of polydrug use on YouTube
}

\section{Kataja, Kati}

2018

Kataja , K, Hakkarainen , P , Koivula , L M P \& Hautala , S 2018 , ' Sharing risk experiences

of polydrug use on YouTube ' , Drugs and Alcohol Today , vol. 18 , no. 3 , pp. 188-197 . https://doi.org/10.1108/DAT

http://hdl.handle.net/10138/299263

https://doi.org/10.1108/DAT-03-2018-0013

acceptedVersion

Downloaded from Helda, University of Helsinki institutional repository.

This is an electronic reprint of the original article.

This reprint may differ from the original in pagination and typographic detail.

Please cite the original version. 


\title{
Sharing risk experiences of polydrug use on YouTube
}

Final draft

Kataja, Kati ${ }^{\text {a) }}$, Hakkarainen, Pekka ${ }^{\text {a) }}$, Koivula, Petteri ${ }^{\text {b) }}$ and Hautala, Sanna ${ }^{\text {c) }}$

a) National Institute for Health and Welfare (THL), Helsinki, Finland

b) University of Helsinki, Finland

c) University of Lapland, Finland

Corresponding author:

\section{Kati Kataja}

E-mail: kati.kataja@thl.fi

\begin{abstract}
:
Purpose:

The purpose of the paper is to discuss what kinds of messages about the risks of polydrug use are mediated in YouTube video blogs and on what kinds of norms and values do the vloggers base these messages.

Design/methodology/approach:

The data consist of twelve YouTube videos where vloggers share their own experiences of the risks and harms of polydrug use. In the analysis, the actantial model of Greimas' theory of structural semiotics was applied.
\end{abstract}

\section{Findings:}

Two main types of videos were identified - sobriety and controlled use - where polydrug use has different meanings. In sobriety videos, polydrug use is presented as the heavy use of multiple substances. In the videos dealing with controlled use, polydrug use is taken as the combining of certain substances. Whereas the sobriety videos emphasized total abstinence from all substances due to their destructiveness, the videos about controlled use emphasized risk awareness when combining substances. Despite modern digital media and a new generation operating in this space, the messages of the risks of polydrug use mainly repeat those of familiar discourses.

Originality/value:

This paper offers an analytical insight into the ways in which the risks of polydrug use are conceptualized in a YouTube context that is increasingly gaining a foothold among the youth. Greimas' actantial model offers a fruitful tool to find semiotic meanings that hide under the surface. The model has not been applied in previous drug research.

Keywords: polydrug use; YouTube, vlogging, Greimas' actantial model, sobriety, harm reduction 


\section{Introduction: An era of the YouTube-generation}

The growing popularity of YouTube characterizes the twenty-first century. According to Burgess and Green (2009), YouTube is a dynamic cultural system that emphasizes user participation, as it functions as a platform for both creating and distributing popular culture. Especially among the youth, YouTube has reached a focal position, being the most popular form of social media (Anderson and Jiang, 2018). This generation, often also called 'digital natives', has grown up in a world where the use of digital technologies belongs to everyday life (Thomas, 2011).

Vlogging means online blogging with video content, and it has become more popular in recent times. According to Veer (2012), vlogs constitute a particular setting that functions on its own terms. He calls this space the 'vlogosphere'. YouTube forms a platform that is, through video casting, available for everyone to practice self-presentation, which Burgess and Green (2009) call empowering exhibitionism. Gurak and Antonijevic (2008) have noted that in vlogging, the boundaries between the public and private spheres are blurred: they contain something very personal, sort of like online diaries that are simultaneously broadcast to the whole world. Bakker and Sadaba (2008) stress the interactive nature of vlogging, and as such they have an important role in self-reflection and identity construction. Vlogs are an open invitation to the audience to react, respond and participate in a dialogue with the vlogger. Additionally, vlogs provide a context to address topics that are of a very sensitive nature, some of them generally considered to be taboo (Lee, 2011; Raun, 2015; Gibson, 2016). Thus, the use of illicit drugs is one topic addressed in YouTube vlogs. Consequently, vlogs also operate as a platform for the information concerning the harms and risks related to drug use.

Polydrug use is a general term describing a wide variety of substance use behaviours and it has become a subject of scientific and social debate (e.g. EMCDDA, 2009; Klein, 2013). For example, polydrug use can be categorized with regard to the timing of the ingestion of multiple substances, and a rough dichotomy of concurrent (with varying time frame) and simultaneous polydrug use has generally been applied in many studies (e.g. Midanik et al., 2007; Quintero, 2009). This study focuses on those YouTube vlog videos that discuss simultaneous polydrug use: a criterion for eligibility is that the videos clearly focus on the overlapping effects of two or more different substances taken at one point in time. More specifically, 
focusing especially on vlog videos dealing with the risks and harms of polydrug use is interesting because polydrug use is a specific pattern of drug use with its own special risks. Earlier research has also largely focused on the risks related to polydrug use emphasizing its harmful social and health effects (Stevens et al., 2007; Medina and Shear, 2007; Kelly et al., 2015). Some studies, however, have explored the phenomenon also through non-problematizing lenses (Quintero, 2009; Hunt et al., 2009).

Regarding the use of illicit drugs, vlogging may also be understood as a context for harm reduction. Manning (2014) mentions that within YouTube, a kind of drug education is found that is different from official one. Official drug education may be criticized and challenged by the vlogs due to the fact that the information it provides is not based on personal experiences of drug use. Risk information of drug use not produced by professional agents but ordinary people can be called vernacular harm reduction (Manning, 2013). For young people who seek information the vernacular content may be taken more seriously than the official drug education (Manning, 2014). With respect to this, Kataja's and colleagues' study on combining substances (2018) shows specifically that expertise by experience has been shown to gain authority within users' own status hierarchies in online discussion forums.

In addition, some try to earn money or even make a living out of vlogging by signing contracts with commercial agents, which results in sponsored content: vlogs may include advertisements for brands, product placement and affiliated links. Earlier studies on online marketing has shown that advertising has a great influence on YouTube viewers' attitudes, values and consumer choices (e.g. Smith et al., 2012; Dehghani et al., 2016). For commercial agents to take interest, vloggers generally have to reach the critical mass of followers by being somewhat innovative and pro-social. From this point of view, vlogging aspires to make an impression on one's audience because more views, clicks and shares mean more money. This raises questions as to whether commercial interests and other motives have a tensioned relation (Burgess and Green, 2009). 
Research questions

This study explores personal experiences of risks and harms of polydrug use presented in YouTube vlogs by asking the following questions:

1) How is polydrug use performed in the YouTube vlogs that deal with personal risk experiences of polydrug use?

2) What kinds of messages about the risks of polydrug use do vloggers mediate in their videos?

3) On what kinds of norms and values do the vloggers base their messages?

Reflecting the empirical findings of the study from a broader perspective, this paper discusses to what extent the users' acts may serve to create visibility and publicity for their expressions of self, to practice harm reduction or possibly to earn a living. Overall, there are only a few studies that explore YouTube videos that have drug use content (e.g. Manning, 2013; 2014; Lange et al., 2010; Casselman and Heinrich, 2011). YouTube vlogs that focus especially on polydrug use have not been studied before.

\section{Data and Methods}

The data of the study consist of YouTube vlog videos in which vloggers share their own risk experiences of polydrug use. The search was first conducted in June 2016 and the data was updated by another search in May 2018. The keywords Polydrug, Combo drug use, Combining drugs, Multiple drugs, My combo drug experience, My experience mixing drugs, My mixed drugs experience, and Drug combinations were used. These exact word combinations were the results of a multistage testing to find the most suited keywords to filter videos that contained wanted material. Namely, videos concerning personal risk experiences of polydrug use appeared to be difficult to sift from all the material that dealt with polydrug use (e.g. official drug education). Both searches resulted in altogether 27 YouTube videos, from which those that were not vlogs (but were for example live videos of intoxication) and those where polydrug appeared to be only a minor issue were excluded. Thereafter, the sample comprised 20 videos where the vloggers share their 
personal experiences of polydrug use, highlighting different aspects of it. Applying Paul Manning's (2014) categorization of different YouTube videos having drug use content, these videos were then classified either as celebratory, reflective or cautionary. Two of the videos could be categorized as celebratory as the intended meaning in them was to celebrate the pleasures or to make fun of the intoxication. Six videos could be seen as reflective, as in them, the vloggers reflected their relation to drugs in a more cerebral or philosophic manner; risks were not their primary content. The last twelve videos discuss the personal risk experiences of polydrug use being mainly cautionary out of character. In these videos, viewers were directly informed and warned about the risks, harms and dangers related to polydrug use. Due to their risk content, these twelve videos were considered eligible for the final data of this analysis. The data search and categorization were conducted by two researchers and the discrepancies were resolved by discussions. The selected videos are listed in Table 1.

Table 1: Twelve YouTube video blogs selected for the final data.

\begin{tabular}{|c|c|c|c|c|}
\hline Video & $\begin{array}{l}\text { Gender } \\
\text { (assumed by } \\
\text { the authors) }\end{array}$ & $\begin{array}{l}\text { Views } \\
\text { (by 29 May } \\
2018 \text { ) }\end{array}$ & $\begin{array}{l}\text { Date of } \\
\text { publication }\end{array}$ & $\begin{array}{l}\text { length } \\
\text { (min:sec) }\end{array}$ \\
\hline $\begin{array}{l}\text { 1. My story on drug abuse. Hopefully a } \\
\text { message for teens. }\end{array}$ & female & 29890 & 22 Sept 2011 & $14: 30$ \\
\hline $\begin{array}{l}\text { 2. LSD \& MDMA EXPERIENCE (and why } \\
\text { I believe in illuminati reptilians) }\end{array}$ & male & 28492 & 22 Dec. 2011 & $8: 45$ \\
\hline 3. $\quad$ My Story - Drugs and Self Harm & female & 5825 & 22 June 2013 & $7: 01$ \\
\hline $\begin{array}{l}\text { 4. My past as a Drug User, Vegan Dogma } \\
\text { rant \& Eco shopping }\end{array}$ & female & 248185 & 20 June 2014 & $15: 12$ \\
\hline $\begin{array}{l}\text { 5. The Dangers and Deadly Consequences of } \\
\text { Mixing Drugs }\end{array}$ & male & 2696 & 2 July 2015 & $4: 14$ \\
\hline $\begin{array}{l}\text { 6. Mixing Benzodiazepines and Alcohol... } \\
\text { My experience } \mathrm{n} \text { advice. }\end{array}$ & male & 25166 & 16 Aug 2015 & $15: 13$ \\
\hline $\begin{array}{l}\text { My Addiction Story. Drugs + Alcohol. } \\
\text { Total Transparency }\end{array}$ & female & 119887 & 8 Dec 2015 & $10: 25$ \\
\hline $\begin{array}{l}\text { 8. } 7 \text { DAY COMA *THE EPIC, TRAGIC } \\
\text { TALE* }\end{array}$ & female & 5810 & 23 May 2016 & $24: 33$ \\
\hline 9. Nexus Flipping: A First Experience & male & 592951 & 19 Aug 2016 & $18: 15$ \\
\hline 10. How drug combinations should be done & male & 136 & 2 Sept 2017 & 11:5 \\
\hline $\begin{array}{l}\text { 11. My first bad trip experience (Candy } \\
\text { flipping / LSD + MDMA) }\end{array}$ & female & 96025 & 4 Nov 2017 & $2: 52$ \\
\hline $\begin{array}{l}\text { 12. Drug Combinations - The Good and The } \\
\text { Bad }\end{array}$ & male & 163 & 19 Feb 2018 & $9: 55$ \\
\hline
\end{tabular}


Altogether, these twelve videos have been viewed 1155226 times at the time of writing the paper. In these videos, the vloggers film themselves in different places. With the selected place, the vlogger opens something personal, which comprises a part of the mediated message. The videos were very often filmed in the vlogger's own bedroom with personal furnishings, textiles and other items in the background representing private space and giving an authentic and genuine impression. Besides the space, personal lives may be revealed through hairstyle, clothing and accessories. The outward appearance varied from revealing, striking and sexualized to very inconspicuous, simple and plain. Moreover, the vloggers have included some other elements to their videos such as background music or subheadings to disentangle different sections of the story. In one video, the story was mainly told by written notes and one video was rather an audio blog as the visual part was replaced by a video game. In eight videos, the vlogger sat stably, but four of them included action: walking in a flat or in nature, cooking, driving a car or shopping. Four of the most viewed vlogs had commercial connections containing advertising material by the time of the data collection.

Six of the vloggers were female, and six were male. As for age, they were young adults of about 20-30 years old. Because the search keywords were in English, it is likely that all the vloggers were from Englishspeaking countries. All of the studied vloggers' vlogs consist of a series of videos where the topics touched upon, in addition to drug use experiences, other subjects such as sexuality or self-destructiveness. Therefore, the number of views for each video shown in Table 1 does not necessarily correlate with the popularity of that particular video but may imply the vlogger's own popularity and large following.

Analysis: How to unpack the abundant information of the videos?

Audiovisual social media, animated pictures, motion and a storyline make the vlog data rich and eclectic. Therefore, the abundance of information needed to be structured to systematically analyze the data. In order to grasp the issues constituting the diversity of the data, the information was deconstructed and reorganized by applying the actantial model of Greimas' theory of structural semiotics (Chandler, 2007). By means of Greimas' actantial model, narrative text can be analyzed on two different levels: 1) Through the syntagmatic surface that concerns the linguistic and observed level of the text, 2) the deeper level of the semantic structure can be unearthed, bringing the underlying and hidden meanings, and norms and values of the 
messages forward (Greimas and Courtés, 1982; Greimas, 1987). With the help of the model, especially action that is embedded in a narrative text can be identified and dismantled. Therefore, the model is a fertile tool for analyzing the messages communicated through the videos by offering a way of finding characteristics that might otherwise go unnoticed.

In the model (Figure 1), action is portrayed by six actants, which may be people as well as material or abstract issues or other non-human things, and they are set on three axes: the axis of desire, the axis of power, and the axis of knowledge. The axis of desire contains two actants, the subject that directs toward an object (e.g. the Prince wants to marry the Princess). In the axis of power, the helper aids the subject in reaching its object, while the opponent represents obstacles in this pursuit (e.g. the sword against the dragon). Finally, the axis of knowledge concerns the sender that operates in the background as an initiator of the action (e.g. the King requests the Prince to rescue the Princess), and the receiver is the party or quarter that ultimately benefits when the subject attains its object (e.g. the future and the continuity of the Kingdom) (Greimas, 1966; Hebért, 2011).

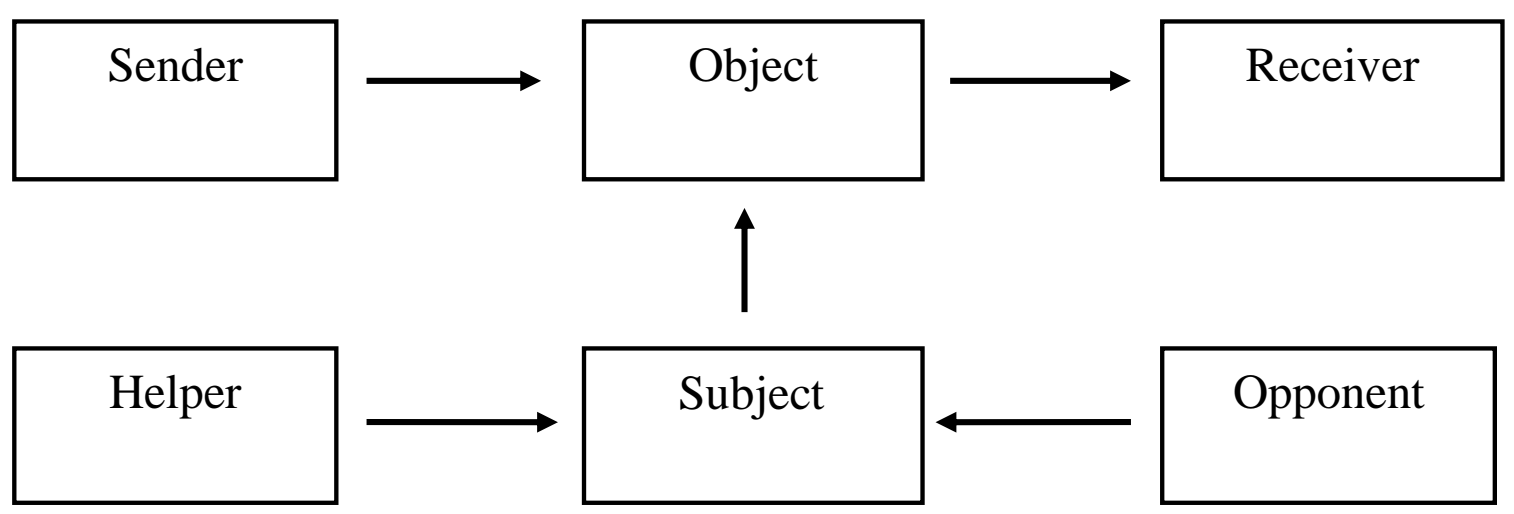

Figure 1: A simplified illustration of Greimas' actantial model (Hebért, 2011). 


\section{Ethical considerations}

Ethical considerations concerning online data are generally complex, especially from the standpoint of whether the data should be regarded as public or private. First, from all the online content, vlogging could be considered to be public: it is purposively and consciously produced and published material, unlike live videos of intoxicated people who might consider the situation to be private. As it is public material, informed consent is not needed. Second, researching vlogs requires balancing between preserving the anonymity and crediting the vloggers for their productions. In this paper, it was decided to not anonymize the data, specifically due to copyright issues. Third, the actantial model as a research method guarantees the transparency of the analysis, showing how the study is conducted, the results are concluded and final interpretations are made. In order to enhance the reliability of the study, the data search and analysis were conducted by two researchers.

\section{Results}

On the basis of their primary message, the twelve videos could be divided into two types: (1) Sobriety and (2) Controlled use. The objects of these two types were different, and they also defined the other actants in the narratives. In the following subchapters, the actants of the two vlog video types and the message that the vloggers aim to convey to their audience are briefly described.

\section{Sobriety videos}

In five of the videos, the subjects are six women telling their personal story of their experiences of drug use. All these videos contained particularly sensitive topics such as painful incidents. A clear object was complete sobriety, i.e. total disengagement from all drug use. In these videos, polydrug use manifests a heavy, heedless and reckless consumption of multiple substances. All those videos followed a certain dramatic pattern. The story begins with the grounding in which polydrug use is first presented as being a solution for some other problem such as depression, self-destructiveness, eating disorder, low self-esteem, loneliness and 
getting teased. '...I started seeing signs again: dismissed, like a burden, belittled. I officially hit my break point. I fell in love with drugs' (v3). In time, heavy drug use does not seem to provide any relief but becomes a problem in itself. The situation escalates into a blind alley, and the vlogger says that there is no other option than making a radical change in lifestyle. The hard trial is presented as worth it. This experience the vloggers want to share with their followers.

The senders pushing towards this object were many. First, negative emotions such as shame and guilt were brought up in some videos. Near death experiences were also portrayed as an alarm which led to sobriety. 'I was fallen over against the couch with my arm out, needle on the floor and I was turning blue... I was blue blue like dead blue... I flatlined for two minutes and 32 seconds as my body shut down, all my organs shut down, my brain shut down' (v8). Reading between the lines many of the sobriety videos implied that the original senders were the normative ideals of society, which rule out all drug use and emphasizes health and sobriety as an ideal way of life.

The greatest opponents in the vloggers' battle were somehow related to drugs and the drug use scene. The substances themselves were presented as absolute enemies. They are blamed for being the reason for not reaching their dreams and a happy life: 'This [cocaine] is part of the thing that really ruined my dance

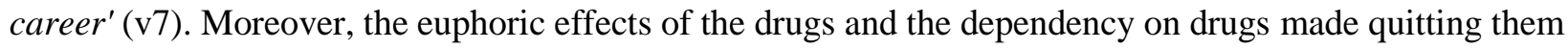
challenging. 'If you're an addict you know that, I just felt like I had to get high like nothing else mattered, I had to get my hands on something I had to get high because all that talk of heroin and the orgasmic feeling you'll get shooting up just made me want it so bad' (v8). Especially friends and other people around them using drugs tended to tie the vloggers to their old habits: 'We were living there and we're doing okay for a while, then we started meeting people. Well, our next door neighbour was a meth dealer and meth addict, and people below us, they were heroin dealers so we had the best of both worlds right there. So we started using drugs on and off again' (v1). On the other hand, an unstable lifestyle in general, and mental illness were also seen as hampering the sobriety goals, especially when drug use functions as a means of selfmedication. 'We all basically said goodbye and watched him [boyfriend] die in front of us, so I kind of went on a downward spiral after that, I couldn't handle it. I didn't cry that much... I started rubbing myself with 
alcohol and drugs again' (v1). Overall, in some videos, the whole society represents the opponent 'We are put a lot more shit from our family and society and all that' (v8).

Helpers in these battles were most of all the persistent close people who did not give up: 'And eventually my dad found out [that I used cocaine] and made me come back to Ohio, which at the time was really scary and a really big relief at the same time. So I came back to Ohio' (v7). Detoxification and treatment programs were described as prerequisites for succeeding in life, and as such they had an essential role as helpers: 'Getting to talk to the people that are in the group that are going through the same things with you is amazing... it's really encouraging and we're like a big family, like a big support group' (v1). Plans for the future and a healthy lifestyle, especially the potential wellbeing brought from these things, were reported to have hugely helped the vloggers: 'Now I'm getting that same high, I'm feeling amazing, I could dance for hours because of my diet, because of my lifestyle. I don't need any fake rubbish to feel amazing and to be vibrated, to be my best. I'm getting it from this lifestyle' (v4). Finally, the making of vlogs and the people following them were also seen as helpers in the struggle.

Overall, the most common messages passed on through these videos were the ideology of sobriety and the lessons learned through the vloggers' own battles, portraying a drug-free world, a healthier youth and a healthier future for society, the wellbeing of humans, animals and nature. These could be interpreted as receivers of the sobriety videos. The moral or the statement that the vloggers wanted to give to their audience was to encourage other people who are striving in a similar situation. 'You can always give yourself a second chance that there's always another chance for you to be happy and sober and you can actually have a reason to live in and to set goals that you need to set or fulfil the dreams that you want' (v1).

\section{Controlled use videos}

Seven of the studied videos approached polydrug use from a different angle. In these videos, the vloggers did not go as deep into their private lives as the vloggers telling the sobriety story. One of them was made by a female and six of them were males who represent the subjects of their stories. Cautioning others on the risks of combining drugs was central in them as well, but the main object was controlled drug use and risk 
avoidance in order to get more pleasure from the intoxication and avoid harm: 'This video is going to be about just generically drug combinations and just a few cautions you should take' (v10); 'Drugs can be really ruthless and they should be respected' (12). Mostly the vloggers explicated their own frightening experience, so as to share the lesson they had learned with their audience. Two of the vlogs discussed the risks of drug combinations on a more general level, although still basing their knowledge on their own experiences.

In most of these videos, the sender was usually the desire to maximize the pleasure 'When you want to try new things and you want to push your high to the limit, you start doing speed balls [opiates and stimulants]'(v5). For example, pre-game parties that are typical among young adults included mixing benzodiazepines with alcohol 'Let's take two of these blue footballs [Xanax], pre-game a little bit you know, have four beers. (v6). Moreover, experimenting with drugs and self-discovery were also mentioned as motives for combining 'Believe me, I'm not doing psychedelics and say, yeah, let's fucked up, No. I'm learning about myself and how the brains work' (v11).

Mixing substances may cause unexpected consequences, which were presented as the greatest opponents in the controlled use videos. Particularly, friends who incite to heedless use habits are placed in the role of opponent when pursuing controlled use: 'I remember seeing one of my mom's friends... I see him, I'm like hey man let's do a shot, let's do a shot, let's do some Jack Daniels...' (v6). Moreover, the deceptiveness of the intoxication, paranoia, a bad trip that is especially related to the use of LSD may transform into a sudden opponent and ruin the expected good intoxication: 'I started frying hard; basically I did the misconception, I had so many fucking theories going on in my head about what was fucking going on, but I thought that they [friends] were fucking illuminati cult trying to steal my brain, and my friend and his girlfriend were like the physical carnation of Satan' (v2). In one video, the drugs represent an opponent but differently than in the sobriety stories: namely, they may fail to cause the expected effect: 'I was not only disappointed that it didn't really hit me that hard, I was disappointed that the experience failed to live up to the expectations' (v9). In other words, unlike in the sobriety videos, the opponents were not drugs per se, but some characteristics connected with them. 
Friends, however, also have a significant role as helpers, being for example trip-sitters: 'My friend was actually a fantastic trip-sitter. He told me to sit down, he could see that I was struggling' (v9). Friends appear to be especially important when the situations become critical: 'Have some kind of security mate, like if you're too fucked up or that you can get out of that situation to hospital or whatever' (v10). Most of all, mastering drugs and drug-related information, for instance being aware of the right timing of substance use or avoiding certain combinations, was given the role of helper in these seven videos: 'Personally before doing a combo I like to get a feel of the drug alone for like a few times just so I know what to expect'(v12); 'Everyone who is candy flipped before told me that you need to wait till the acid starts taking in order to take the Molly [MDMA] to have the best experience' (v2).

The receivers of the controlled use videos were first and foremost people who use drugs and potentially learn from the vloggers' bad experiences to deal with drugs with appropriate caution. The vloggers finish their video with concrete advice for their audience. The warning concerns for example the proper preparation for a challenging trip: 'I guess the moral of the story is: don't do really powerful hallucinogens unless you're prepared for it because it's gonna fuck you up man, let me tell you, just kind of fuck with your head in ways that you have no idea, like just chill before you do this shit' (v2). The message may also be to protect the followers from very severe consequences. At best, the video may save someone's life: 'That's my advice to you guys: don't mix them [alcohol and benzodiazepines] because you're going to black out, there's other things that can happen... If you drink too much and take many of them you could possibly go into a coma. You could die' (v6).

\section{Discussion}

The Sobriety videos and the Controlled use videos differ from each other in many respects, probably because they are directed to different audiences. The greatest difference seems to be how the object of action is defined, which then determines the other actants. In some respects, the stories even seem to be the opposites of each other. 
First, in sobriety videos, material items such as drugs symbolize the worst enemy, which stands in the way of reaching the object. By contrast, in the videos dealing with controlled use, drugs even act as helpers towards an ideal intoxication (when properly used). Second, in sobriety videos, negative bodily experiences such as withdrawals are portrayed as helpers that motivate the goal achievement; but in the stories of controlled use, they are expressed as the opponents implying that the use has slipped out of control. On the contrary, positive bodily experiences (being high) are presented as opponents that hamper quitting drugs, as they tempt the users to return to their old habits. In controlled use, naturally, positive bodily experiences, while being the main objective, are also helpers that provide new information about the effects of different substance combinations. Third, as for close people around, they may work as helpers in the pursuit for sobriety, but drug-using friends also strongly endorse the continuation of use, which, when against one's own will, symbolize the opponent. But especially in controlled use, user buddies, in turn, are helpers with whom drug use and inspiring ideas about it are safely shared.

An essential difference between these two video types was that they leaned on different values and ideologies by which the whole message was framed. In sobriety videos, the temperance movement was clearly recognized. In addition, the idea of a healthy lifestyle with ecologically and ethically sustainable choices was explicitly emphasized. In addition, dreams of individual development in the form of education or career, or more widely having a genuinely happy life, were stressed as significant values. In the videos concerning controlled use, the ideologies were not so present or openly articulated. However, in a broader sense, these videos plead for a more liberal outlook on life, according to which drug use is not condemned but drug users are rather seen as smart individualized and responsible consumers who are aware of the risks of their chosen lifestyle.

Both discourses, sobriety and controlled use, seem to surpass a certain level of visibility in order to serve certain goals, for example self-presentation and exhibitionism (Burgess and Green 2009), vernacular advice for reducing the harms of polydrug use (Manning, 2014), or targeting more commercial and monetary interests (Smith et al., 2012; Dehghani et al., 2016). Because expressing personal emotions towards topics considered taboo is one of the main ideas of vlogging (Lee, 2011; Raun, 2015; Gibson, 2016), personal 
experiences of heavy drug use represent genuine self-presentation at its best. Especially stories concerning sobriety with their very sensitive aspects serve the purpose of public exhibitionism. As for vernacular harm reduction, the findings of this study indicate that it takes place in videos that discuss controlled polydrug use. This finding confirms earlier research, which has shown that social media in general constitutes an environment for sharing first-hand knowledge on harm reduction of substance combinations (e.g., Kataja $e t$ al., 2018).

Regarding the vloggers' aim to gain monetary benefits from vlogging about polydrug use, this study shows that this kind of activity exists, both in the videos of sobriety and of controlled use. However, only one-inthree of the studied videos had a clear link to advertisers. That is to say, the contradictions between commercial and other interests do not really seem to characterize YouTube vlogs dealing with the risks of polydrug use (cf. Burgess and Green, 2009). However, it is likely that commercial elements become more common in all kinds of vlogging in the future, along with the ever increasing popularity of YouTube.

Overall, these two video types resemble two familiar risk discourses in drug use: the abstinence discourse (e.g. Peele, 2004) and the harm reduction discourse (e.g. Zinberg, 1984). Partly the videos repeat the same discourse on the destructiveness of drugs presented by the traditional media (e.g., Manning, 2014), but partly they challenge it by providing an alternative view. Thus, the modern domain of the vlogosphere (Veer, 2012) and a new generation (Anderson and Jiang, 2018; Thomas, 2011) that increasingly operates in this space together, has in all probability an effect on public discourse: producing polydrug use as risky but nonetheless manageable and controllable.

The study generated several new angles for future research. For one, it was interesting to find that all vloggers telling the sobriety story were female, and five out of six vloggers talking about controlled use were male. Accordingly, gender seems to matter, which raises questions about different role expectations concerning drug use in YouTube settings (Measham, 2002). Even though this sample does not provide generalizable information, it constitutes an interesting topic worth researching more profoundly. Another topic worth studying would be to include comments on the video in the data, as vlogging is basically meant to be an interactive activity where the primary idea is to get into dialogue with followers (Bakker and 
Sadaba; Manning, 2014). Moreover, as pointed out in earlier research (Hunt, 2009; Quintero, 2009), while being considered risky behaviour, polydrug use has also been loaded with positive expectations. Especially some videos categorized as reflective were about the therapeutic experiences of psychedelics, for which the actantial model would provide a useful approach. As a limitation, as Manning (2014) found, after Google bought YouTube in 2006, videos having drug use content have been censored, which has led to their decrease on the YouTube platform, and this forms a restriction of the study.

\section{Conclusion}

This study offers an analytical insight into the ways in which the risks of polydrug use are performed in a YouTube context. Twelve YouTube video blogs with cautionary content regarding polydrug use were analysed. Greimas' actantial model came in a fruitful method that enabled both to find semiotic meanings that hid under the surface and to structure and classify the rich information found in the YouTube vlogs. Two main types of videos dealing with the risks of polydrug use were identified: sobriety and controlled use. In the sobriety videos, polydrug use is seen as heavy use of multiple substances. In the videos of controlled use, polydrug use manifests as the combining of certain substances. Whereas the sobriety videos emphasize total abstinence from all substances due to their destructiveness, the videos about controlled use take a more liberal stand by emphasizing risk awareness when combining substances. As YouTube is increasingly gaining a foothold especially among the youth, personal risk experiences mediated on that specific platform are likely to affect people's attitudes towards polydrug use and drug use in general.

\section{Acknowledgements}

The article is a part of the research project: "Making sense of polydrug use: prevalence, use patterns and harms" funded by the Academy of Finland (Project Grant 274415). We are very grateful for this support. We would also like to thank the two anonymous Reviewers for their insightful and helpful comments. 


\section{References}

Anderson, M. and Jiang, J. (2018), Teens, social media \& technology 2018. Pew Research Center,

Washington DC, available at: http://assets.pewresearch.org/wp-

content/uploads/sites/14/2018/05/31102617/PI_2018.05.31_TeensTech_FINAL.pdf (accessed 2 June 2018).

Bakker, P. and Sadaba, C. (2008), “The impact of the internet on users”, in Kung, L., Picard, R. and Towse,

R. (Eds.), The Internet and the Mass Media, Sage, London, pp. 17-44.

Burgess, J. and Green, J. (2009), YouTube: online video and participatory culture, Polity Press, Cambridge.

Casselman, I. and Heinrich, M. (2011), "Novel use patterns of Salvia divinorum", Unobtrusive using YouTube. Journal of Ethnopharmacology, Vol. 138 No. 3, pp. 662-667.

Chandler, D. (2007), Semiotics. The basics. $2^{\text {nd }}$ edition. Routledge, New York, NY.

Dehghani, M., Khorram Niaki, M., Ramezani, I. and Sali, R. (2016), "Evaluating the influence of YouTube for attraction of young customers", Computers in Human Behavior, Vol. 59, pp. 165-172.

EMCDDA (2009), Selected issue. Polydrug use: patterns and responses, European Monitoring Centre for Drugs and Drug Addiction, Lisbon. 
Gibson, M. (2016), "YouTube and bereavement vlogging: Emotional exchange between strangers", Journal of Sociology, Vol. 52 No. 4, pp. 631-645.

Greimas, A. J. and Courtés, J. (1982), Semiotics and language: An analytical dictionary, Indiana University Press, Bloomington.

Greimas, A.J. (1966), Structural semantics. An attempt at a method, University of Nebraska Press, Lincoln.

Greimas, A.J. (1987), On meaning. Selected writings in semiotic theory, Frances Pinter, London.

Gurak, L.J. and Antonijevic, S. (2008), "The psychology of blogging. You, me, and everyone in between”, American Behavioral Scientist, Vol. 52 No. 1, pp. 60-68.

Hebért, L. (2011), “Tools for text and image analysis an introduction to applied semiotics", available at: http://www.signosemio.com/documents/Louis-Hebert-Tools-for-Texts-and-Images.pdf (accessed 22 March 2018).

Hunt, G.P., Bailey, N., Evans, K. and Moloney, M. (2009), “Combining different substances in the dance scene: enhancing pleasure, managing risk and timing effects", Journal of Drug Issues, Vol. 39 No. 3, pp. $495-522$. 
Kataja, K., Törrönen, J., Hakkarainen, P. and Tigerstedt, C. (2018), ”A virtual academy of polydrug use. Masters, novices and the art of combinations", Nordic Studies on Alcohol and Drugs, DOI:

$10.1177 / 1455072518770351$.

Kelly, A.B., Evans-Whipp, T.J., Smith, R., Chan, G.C.K., Toumbourou, J.W., Patton, G.C., Hemphill, S.A., Hall, W.D. and Catalano, R.F. (2015), “A longitudinal study of the association of adolescent polydrug use, alcohol use and high school non-completion", Addiction, Vol. 110 No. 4, pp. 627-635.

Klein, A. (2013), "Poly and mono: Reflections on the validity of 'poly drug use"”, in Adams, C., Valdstein, A., Sessa, B., Luke, D. and King, D. (Eds.), Breaking convention: Essays on psychedelic consciousness, Strange Attractor Press, Devizes, pp. 162-171.

Lange, J.E., Daniel, J., Homer, K., Reed, M.B. and Clapp, J.D. (2010), "Salvia divinorum: effects use among YouTube users", Drug and Alcohol Dependence, Vol 108 No. 1-2, pp. 138-140.

Lee, S. L. (2011), "Exploring emotional expressions on YouTube through the lens of media system dependency theory”, New Media \& Society, Vol. 14 No. 3, pp. 457-475.

Manning, P. (2013), “YouTube, ‘drug videos’ and drug education”, Drugs: Education, Prevention and Policy, Vol 20 No. 2, pp. 120-130.

Manning, P. (2014), Drugs and popular culture in the age of new media, Routledge, New York, NY. 
Measham, F. (2002), ““'Doing gender” - “doing drugs”: conceptualizing the gendering of drugs culture”, Contemporary Drug Problems, Vol. 29, pp. 335-373.

Medina, K.L. and Shear, P.K. (2007), “Anxiety, depression, and behavioral symptoms of executive dysfunction in ecstasy users: contributions of polydrug use", Drug and Alcohol Dependence, Vol. 87 No. $2-$ 3, pp. 303-311.

Midanik, 1.T., Tam, T.W. and Weisner, C. (2007), “Concurrent and simultaneous drug and alcohol use: results of the 2000 National Alcohol Survey", Drug and Alcohol Dependence, Vol. 90 No. 1, pp. 72-80.

Peele, S. (2004), 7 tools to beat addiction, Three Rivers Press, New York, NY.

Quintero, G. (2009), “A cultural analysis of collegiate polydrug use”, Journal of Psychoactive Drugs, Vol. 41 No. 1, pp. 39-47.

Raun, T. (2015), "Video blogging as a vehicle of transformation: Exploring the intersection between trans identity and information technology", International Journal of Cultural Studies, Vol. 18 No. 3, pp. 365-378.

Smith, A.N., Fischer, E. and Yongjian, C. (2012), "How does brand-related user-generated content differ across YouTube, Facebook, and Twitter?” Journal of Interactive Marketing Vol. 26, pp. 102-113. 
Stevens, A., Peschk, I. and Schwarz, J. (2007), "Implicit learning, executive function and hedonic activity in chronic polydrug abusers, currently abstinent polydrug abusers and controls", Addiction, Vol. 102, pp. 937946.

Thomas, M. (Ed.)(2011), Deconstructing digital natives. Young people, technology and the new literacies, Routledge, New York, NY.

Veer, E. (2012), "Hiding in plain sight: 'secret' anorexia nervosa communities on YouTube”, Advances in Consumer Research, Vol. 38, pp. 256-261.

Zinberg, N.E. (1984), Drug, set, setting. The basis for controlled intoxicant use, Yale University Press, New York, NY. 